\title{
Epidemiological and Histopathological Characteristics of Esophageal Cancers in Cameroon
}

\author{
Jean Paul Ndamba Engbang ${ }^{1,2,{ }^{*} \text {, Basile Essaola }}{ }^{1}$, Servais Eloumou ${ }^{1,5}$, Zacharie Sando ${ }^{3,4}$, \\ Ebock Yvette Takang ${ }^{1}$, Godefroy Simo $^{6}$, André Moune ${ }^{7}$, Roger Gilbert Ateba ${ }^{5,8}$, Amadou Fewou ${ }^{4,9}$ \\ ${ }^{1}$ Faculty of Medicine and Pharmaceutical Sciences, The University of Douala, Douala, Cameroon \\ ${ }^{2}$ Laquintinie Hospital of Douala, Douala, Cameroon \\ ${ }^{3}$ Yaoundé General Hospital, Yaoundé, Cameroon \\ ${ }^{4}$ Faculty of Medicine and Biomedical Sciences, The University of Yaoundé I, Yaoundé, Cameroon \\ ${ }^{5}$ Douala Gyneco-Pediatric Hospital, Douala, Cameroon \\ ${ }^{6}$ Bio-Medical and Cancer Center of Bafoussam, Bafoussam, Cameroon \\ ${ }^{7}$ Anapathos Laboratory, Douala, Cameroon \\ ${ }^{8}$ Pravilna Laboratory, Douala, Cameroon \\ ${ }^{9}$ Douala General Hospital, Douala, Cameroon
}

Email address:

jean_pen@yahoo.ca (J. P. N. Engbang),jpauleng@gmail.com (J. P. N. Engbang)

${ }^{*}$ Corresponding author

\section{To cite this article:}

Jean Paul Ndamba Engbang, Basile Essaola, Servais Eloumou, Zacharie Sando, Ebock Yvette Takang, Godefroy Simo, André Moune, Roger Gilbert Ateba, Amadou Fewou. Epidemiological and Histopathological Characteristics of Esophageal Cancers in Cameroon. Cancer Research Journal. Vol. 7, No. 4, 2019, pp. 150-156. doi: 10.11648/j.crj.20190704.15

Received: September 14, 2019; Accepted: October 7, 2019; Published: November 14, 2019

\begin{abstract}
To describe the epidemiological and histopathological aspects of esophageal cancers in Cameroon. A retrospective study was carried out over a period of 13 years (January 2004-December 2016) in anatomopathological and gastroenterological departments, in five different regions in Cameroon. Only cases of confirmed histological diagnosis of esophageal cancers were included. Information was retried using a performed question which included questions of sociodemographic data, anatomical site, gross appearance, type specimens, histological type. Data statistical analysis was done using Statistical Package for Social Sciences (SPSS) software version 20.0. We registered 89 cases of esophageal Cancers within the study period. It was the $4^{\text {th }}$ frequent malignancy of the gastrointestinal tract $(6.33 \%)$ of all cases. The mean age was $54.89 \pm 11.22$ years, predominant at $75.28 \%$ in the male sex. Smoking was the predominant risk factor among the identified factors associated with the risk of that cancer $(21.35 \%)$. Lesions of the endoscoy were mostly ulcerative $(44.44 \%)$ with preferential sites being the lower third portion of the oesophagus (63.33\%). 83.15\% (74 cases) specimens were biopsies. Squamous cell carcinoma (SCC) was the most frequent histological type $(52.81 \%)$, followed by adenocarcinoma (ADK). Malignant tumors of the esophagus are predominantly male in Cameroon and occur mainly in subjects over 50 years. Their incidence is strongly associated with alcohol-toxic intoxication. The tumor lesions sit mainly in the lower third of the organ. The most common histological type is squamous cell carcinoma.
\end{abstract}

Keywords: Cancer, Esophagus, Epidemiology, Histopathology, Cameroon

\section{Introduction}

Esophageal Cancer (EC) is the eighth most common cancer worldwide and the sixth leading cause of cancer related mortality [1]. Majority of oesophageal cancers (80\%) are reported in more deprived nations [2]. Regions with the largest incidence: mortality ratio in men included Southern Africa (1.47), Western Europe (1.27), and South America (1.23). In women, the highest ratios were reported for female in Western Europe (3.57), Northern Europe (1.63) and South 
America (1.34) [2]. Incidence and mortality is geographically varied with a particularly high burden in East Asia and Eastern/Southern Africa where esophageal squamous cell carcinoma (SCC) predominates over adenocarcinoma (AC) $[3,4]$. Interestingly, there is a dichotomy between the high incidence of esophageal SCC in East Africa and low incidence in West Africa [3]. Unfortunately, it is often associated with poor prognosis with 5-year survival, ranging from 4 to $40 \%$ depending on stage, and an $18 \%$ overall 5 year survival [5]. Although SCCs historically consist of the majority of all cases of this cancer, in recent years we have observed a rapid rise of $\mathrm{AC}$ in western countries [6, 7]. The two main histological forms are squamous cell carcinoma, the most common form affecting and mostly observed in Asia, and esophageal adenocarcinoma, less common worldwide, but with a higher incidence in Caucasians [8]. According to some authors, squamous cell carcinoma is related to alcohol and tobacco or to the habitual consumption of hot drinks or foods. Adenocarcinoma is developed in the lower esophagus on glandular metaplasia and is linked to oesophageal reflux, excess food, animal calories and insufficient physical activity, hence the relationship with excess weight [9]. High maize consumption currently appears to correlate with the risk of esophageal cancer occurring in Africa through its mycotoxin contamination: fumonisin, a potential carcinogen for humans [10]. In Cameroon, few studies has be done, and were limited at the regional level. According to the study done in 2016, on esophageal cancer in the city of Douala, esophageal cancer this pathology ranked 4th among digestive cancers with 26 cases out of 410 digestive cancers $(6.34 \%)$; men were more affected with either sex ratio of 2.7. The histological types found were squamous cell carcinoma and adenocarcinoma of the esophagus [11]. The scarcity of national data and the significant role played by esophageal cancer in the littoral region, according to the previous study, lead us to take a closer interest in the epidemiological and histopathological profiles of this serious disease territorially over the last twelve years. This allows not only national data, but also recent, leading to a mastery of this pathology in our context.

\section{Material and Methods}

This was a retrospective and descriptive study of patients with esophageal cancers confirmed histologically, diagnosed between January 2004 and December 2016. Data was obtained from histopathology, gastroenterology records of different health centers in five regions of Cameroon. Ethics Committee of all the concerned institutions approved the study protocol. The samples examined were mainly composed of biopsies and surgical specimens fixed in $10 \%$ formalin and processed according to the usual techniques of paraffin embedding, microtome cutting and staining with hematoxylineosin. The information obtained included frequency, age, sex and histological type of the tumor. Data entry was done using computer based statistical Package for Social Sciences (SPSS) version 20. The descriptive statistics elements were used to calculate the frequencies and proportions

\section{Results}

\subsection{Epidemiological Aspects}

\subsubsection{Frequency of Cancers by Segment of the Digestive Tract}

In total, 1407 cases of cancers of the gastrointestinal tract were collected, from 2004 to 2016. Oesophageal cancer (89 cases, $6.33 \%$ ) was in the fifth position after the stomach, the colon, the rectum and the anal cancer.

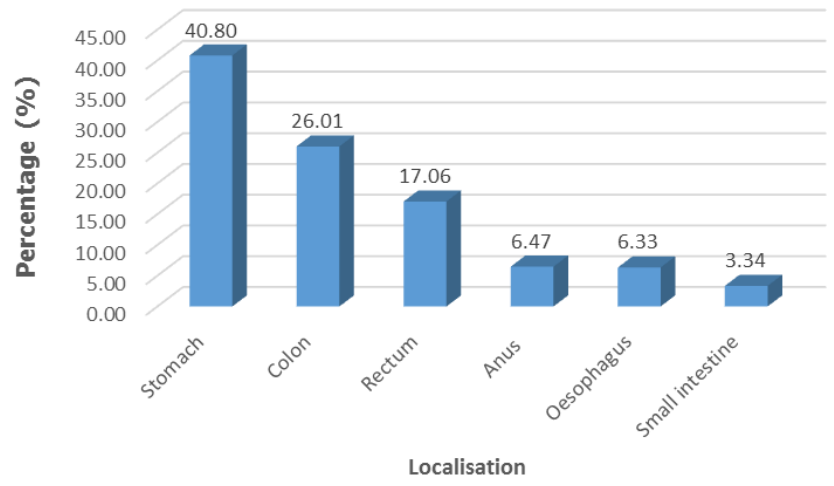

Figure 1. Distribution of cancers according to the segment of the digestive tube.

\subsubsection{Sex}

In Table 1, stomach cancer was in the first rank (312 cases, $40.63 \%$ ), and esophageal cancer (67 cases, $8.72 \%$ ), in the fourth rank, in males. In females, the stomach was also the most affected gastrointestinal tract (262 cases, $41.00 \%$ ), and esophagus, the sixth one (22 cases, 3.44\%).

Table 1. Distribution of gastrointestinal cancers by seat and sex.

\begin{tabular}{lllllll}
\hline \multirow{2}{*}{ Organ } & \multicolumn{2}{l}{ Males } & \multicolumn{3}{l}{ Females } & Total \\
\cline { 2 - 7 } & Eff & \% & Eff & \% & Eff & \% \\
\hline Stomach & 312 & 40,63 & 262 & 41,00 & 574 & 40,80 \\
Colon & 193 & 25,13 & 173 & 27,07 & 366 & 26,01 \\
Rectum & 130 & 16,93 & 110 & 17,21 & 240 & 17,06 \\
Anus & 42 & 5,47 & 49 & 7,67 & 91 & 6,47 \\
Oesophagus & 67 & 8,72 & 22 & 3,44 & 89 & 6,33 \\
S. intestine & 24 & 3,13 & 23 & 3,60 & 47 & 3,34 \\
& 768 & 100,00 & 639 & 100,00 & 1407 & 100,00 \\
\hline
\end{tabular}

Eff - Effective, \% - Percentage, S-Small

Of the 89 patients, the majority of patients were males 67 (75.28\%); the male to female ratio was 3.05:1.

\subsubsection{Age}

The average age of patients was $54.89 \pm 11.22$ years, extremes ranging from 26 to 71 years old. In males, the mean age was 55.44 \pm 11.82 years (extremes: 26-71 years), in females-53.14 \pm 12.92 years (38-71 years). The peak incidence was noted with patients from 50 to 59 years old with a percentage of $29.21 \%$ (26 cases) and $65.17 \%$ of patients (58 cases) were above 60 years age as shown in Figure 2. 


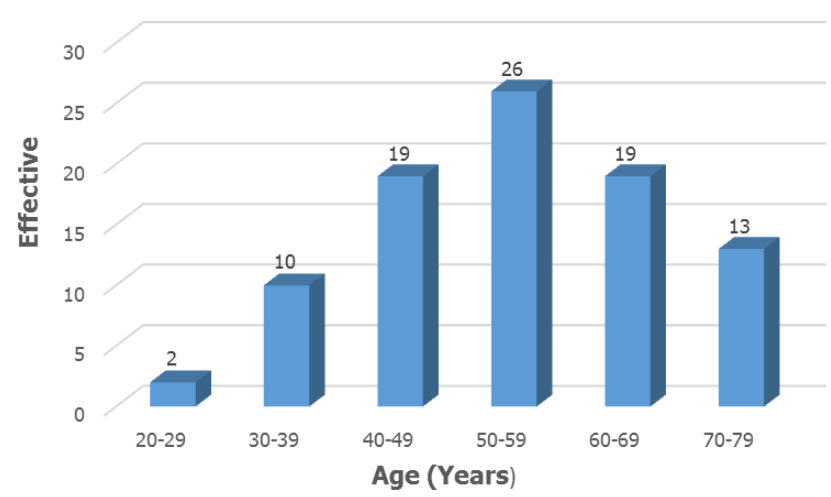

Figure 2. Distribution according to age groups.

\subsubsection{Risk Factors}

Only 55 patients had reported risk factors. Tobacco was the first by these facts (19 cases, 21.35\%) followed by alcohol (17 cases, 19.10\%); While 6.74\% (6 cases) of patients acknowledge that they both consume both (Figure 3).

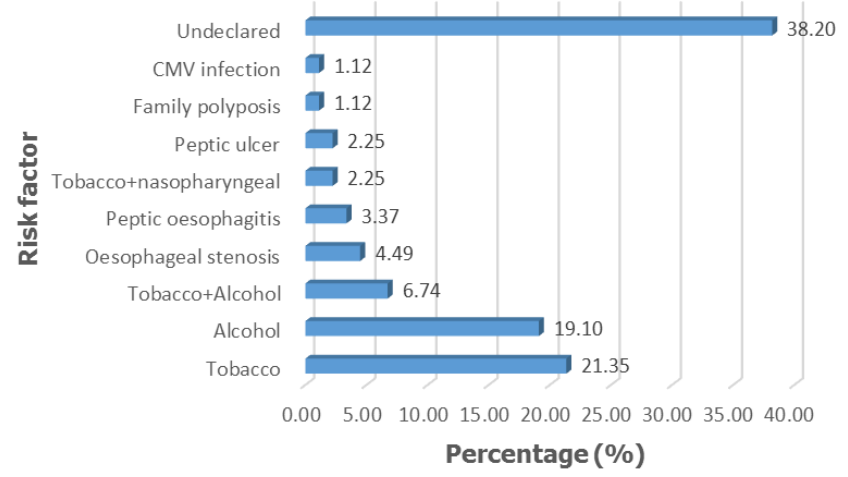

Figure 3. Distribution of cases according to risk factors.

\subsubsection{Anatomical Site}

As showed in figure 4, of the 61 lesions localized to endoscopy, $62.30 \%$ (38 cases) were located in the lower third portion of the esophagus and $15(24.59 \%)$ were in the middle third.

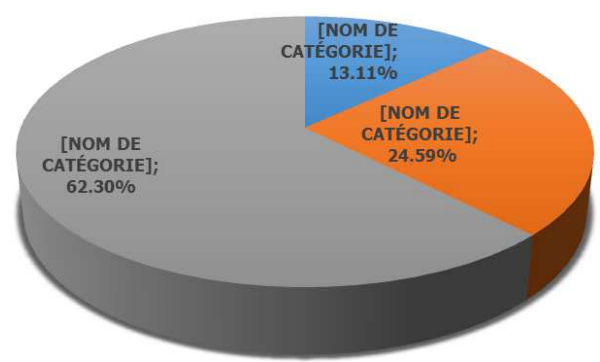

Figure 4. Anatomical site.

\subsection{Histopathology}

\subsubsection{Type of Sample}

In our series, $83.15 \%$ (74 cases) of anatomical specimens submitted for analysis were taken from biopsies.

\subsubsection{Macroscopic Appearance}

As shown in Figure 5, the ulcerated aspect was the most represented with $36 / 89$ cases $(44.44 \%)$, followed by the ulcero-budding appearance with $19.44 \%$ (14 cases).

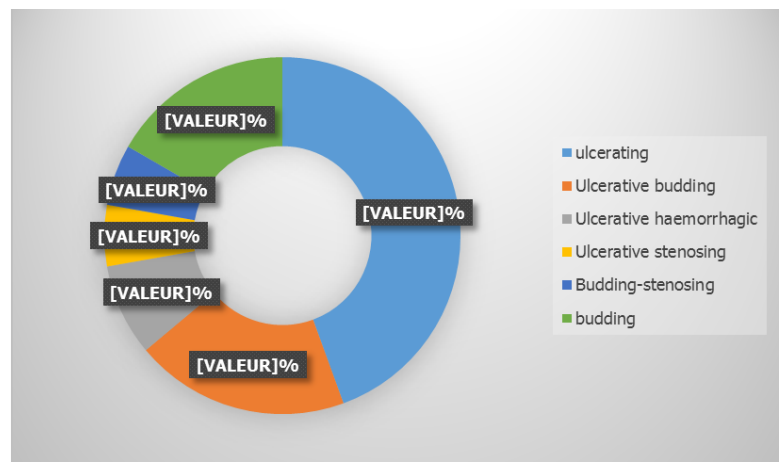

Figure 5. Case distribution according to the macroscopic aspects of the tumor.

\subsubsection{Histological Types}

Squamous cell carcinoma was the most frequent histological type with $52.81 \%$ (47 cases), followed with adenocarcinoma ( $42.70 \%, 38$ cases). It is important to notice that undifferenciated carcinoma was found after 39 years old (Table 2).

Table 2. Distribution of histological types by age group.

\begin{tabular}{|c|c|c|c|c|c|c|c|c|}
\hline Histological types & 20-29 & 30-39 & $40-49$ & $50-59$ & $60-69$ & 70-79 & Total & Percentage \\
\hline Squamous cell carcinoma (SCC) & 1 & 6 & 15 & 12 & 8 & 5 & 47 & 52,81 \\
\hline Adenocarcinoma (ADK) & 1 & 4 & 3 & 12 & 10 & 8 & 38 & 42,70 \\
\hline Undifferenciated Carcinoma (UC) & - & - & 1 & 2 & 1 & - & 4 & 4,49 \\
\hline Total & 2 & 10 & 19 & 25 & 19 & 13 & 89 & 100,00 \\
\hline
\end{tabular}

As showed in table 3, Analyzing 61 of the patients from the 89 patients whose anatomical location information were available, $20.00 \%$ of SCC are located in the upper third portion of the esophagus and $56.68 \%$ in the lower third portion. Concerning ADK, only $68.97 \%$ of cases are found in the lower third of the esophagus and $24.14 \%$ in the middle third.

Table 3. Distribution of histological types according to the anatomical site and sex.

\begin{tabular}{|c|c|c|c|c|c|c|c|c|}
\hline Location & SCC & & ADK & & $\mathbf{U C}$ & & Totol & o/ \\
\hline (esophagus) & Male & Female & Male & Female & Male & Female & Iotal & $\%$ \\
\hline Upper third portion & 3 & 3 & 1 & 1 & & & 8 & 13.11 \\
\hline Middle third portion & 5 & 2 & 5 & 2 & & 1 & 15 & 24.59 \\
\hline Total & 22 & 8 & 21 & 8 & 1 & 1 & 61 & 100.00 \\
\hline
\end{tabular}




\section{Discussion}

In some countries (India, in states such as Karnataka, Tamil Nadu, Kerala, and Assam), Esophageal cancer (EC) is the most common gastrointestinal (GI) malignancy [12]. In our study, Oesophageal cancer ( 89 cases, 6.33\%) was in the fifth position after the stomach, the colon, the rectum and the anal cancer. Harouna et al found that EC represented 3.22\% of digestive cancers in Niger [13]. Henry et al Concerning race, observed a statistical prevalence of SCC in black patients and $\mathrm{ADC}$ in White patients [14]. Brown et al. attributed the high incidence of SCC in black men to various factors, the major ones being high ethylism, tabagism, and low vegetable and fruit ingestion together with low social economic level [15]. But, for Patel et al, in United States, Blacks, compared to other races, had the greatest statistically significant decrease in incidence between 2001-2015 [16]. According to Mir et al, about $90 \%$ of ECs worldwide occur in defined high incidence areas of low and middle-resource countries and economically deprived communities; and those authors thought that Low socio-economic status and general deprivation have been proposed to be one of the many factors for high incidence of EC [17]. We think that our low incidence is probably because of bad orientation of patients (most are consulted in ORL because of dysphagia), or because of insuffisance of specialists (gastroenterologists and oncologists) in the country.

In our study, the majority of patients were males 67 (75.28\%); the male to female ratio was 3.05:1. This result was similar to that of Tettey et al in Ghana, who found a male to female ratio of $4: 1$ [18]. The sex ratio (male to female) all over the world shows significant diversity ranging from 0.85 in Northern Iran to as high as 20.5 in Hispanics $[19,20]$. In a study conducted by Nordenstedt and Seraq, the male to female ratio of esophageal cancer varied according to histology, age and race [20]. In their report, the results showed that for esophageal adenocarcinoma, all races had similar sex- and age- specific incidence patterns with a peak in the male to female ratio in the age group $50-59$ years [20].

In the present study, the average age of patients was 54.89 \pm 11.22 years, extremes ranging from 26 to 71 years of age. In males, the mean age was $55.44 \pm 11.82$ years (extremes: 26 71 years), in females $-53.14 \pm 12.92$ years $(38-71$ years $)$. The peak incidence was noted with patients between 50 to 59 years old with a percentage of $29.21 \%$ (26 cases) and $65.17 \%$ of patients (58 cases) were above 60 years of age. Mustafa et al The majority of the patients in our study were above 60 years of age in both the sexes, with males outnumbering females in all age groups [21]. In Ghana, they found similar age modal like us, with the mean age at diagnosis of 58.4 years and an age range of $27-87$ years. The bulk of the disease presented in the 50 - 59 year group [18]. In both developed and developing countries the modal age presentation of esophageal carcinoma appears to be similar. Both squamous cell carcinoma and adenocarcinoma of the esophagus are infrequent before 40 years of age, beyond which the incidence of each type rises with each decade of life [22]. Most of these patients have identifiable risk factors that could be linked with the genesis of the esophageal disease.

Alcohol (etylism) and tobacco are considered like risk factors in the development of EC. In our study, tobacco was the first by (19 cases, $21.35 \%$ ) followed by alcohol (17 cases, 19.10\%). According to Lin et al, ethylism and tabagism have a synergic effect in EC and the risk depends on exposure length [23]. Wheeler and Redd reported a greater tobacco carcinogenic activity in EC for tar aromatic hydrocarbons and volatile nitrosamines [24]. The action mechanism of etylism (which risk increases with the amount of drinks consumed) remains uncertain and various theories have been proposed, such as mucosa irritation, increased susceptibility to other carcinogens, in addition ensuing dietary deficiency [24]. Alcohol can damage the cellular DNA by decreasing metabolic activity within the cell and therefore reduce detoxification function while promoting oxidation [25]. Alcohol is a solvent, specifically of fat-soluble compounds. Therefore, the hazardous carcinogens within tobacco are able to penetrate the esophageal epithelium easier [26]. Some of the carcinogens in tobacco include aromatic amines, nitrosamines, polycyclic aromatic hydrocarbons, aldehydes and phenols. Research suggests that when a smoker ingests tobacco condensates, it causes tobacco carcinogens, particularly nitrosamines, to come in contact with the esophageal mucosa. There is a direct correlation between the number of cigarettes a smoker smokes per day; the length of time the smoker spends smoking, and the risk of esophageal cancer [27, 28]. Most studies have shown that alcohol is the primary risk factor but smoking in combination with alcohol consumption may have a synergistic effect and increase the relative risk. The relative risk in men who used both heavy tobacco and alcohol was 35.4 in white males and 149.2 in black males compared to men of the same race and region who were non-smokers or drinkers [29].

Obesity is also a factor that increase risk of EC. More specifically, it has been postulated that obesity increases intraabdominal pressure and gastroesophageal reflux by a specific mechanism, although some studies provided contradictory results. On the other hand, adipose tissue itself influences tumor development [30, 31]. Adipocytes and inflammatory cells secrete adipokines and cytokines which are known to promote tumor development. The abundant availability of lipids from adipocytes in the tumor microenvironment, supports tumor progression and uncontrolled growth. Given that adipocytes are a major source of adipokines and energy for the cancer cell, understanding the mechanisms of metabolic symbiosis between cancer cells and adipocytes, should reveal new therapeutic possibilities [27].

Case-control studies conducted in Brazil have demonstrated that other factors like excessive pepper intake, intake of wood stove cooking and ingestion of hightemperature yerba mate, may contribute to EC $[14,32]$. Some 
authors suggested that the common hot beverages or fluids consumption in both sexes may have a role in carcinogenesis of esophageal cancer [33]. Correlation between drinking hot beverages and risk of esophageal cancer has been demonstrated in many studies from different part of the world [17, 34]. It is believed that this long lasting and spontaneous thermal irritation is likely to damage the esophagus and may facilitate carcinogen through the esophagus lining [35]. Moreover, phenol content in the tea was reported to have cancer-promoting effects [36, 37]. The high consumption of maize was also reported as a risk factor in Africa, because of his contamination by mycotoxin and fumonisin [38].

In retrospective studies of $\mathrm{EC}$, red meat consumption, poor oral health, low intake of fresh fruit and vegetables, and low socioeconomic status have been associated with a higher risk of esophageal squamous cell carcinoma. Barrett's esophagus is clearly recognized as a risk factor for $\mathrm{EC}$, and dysplasia remains the only factor useful for identifying patients at increased risk, for the development of esophageal adenocarcinoma in clinical practice [27].

In our series, $13.11 \%$ of lesions were located in the upper third portion of the esophagus, $24.59 \%$ of the middle third portion and $62.30 \%$ in the lower third portion. Tettey et al in Ghana realized that the distribution of esophageal cancer by anatomical location was $129(84.9 \%)$ in the distal third, 18 $(11.8 \%)$ in the middle third and $5(3.3 \%)$ in the upper third [18]. Oumboma et al in Togo in their study found that the majority of lesions was located in the middle and low portions of the esophagus, and others authors had the similar result $[13,38-40]$.

Concerning the macroscopic appearance, the ulcerated aspect was the most represented with $36 / 89$ cases (44.44\%), followed by the ulcero-budding appearance with $19.44 \%$ (14 cases). Mustapha et al found that ulcerative localized was the most common morphology [21]. In Japan, two most frequent morphological types were "ulcerative localized" and "ulcerated infiltrative" type (JSED Types 2 and 3). Association of macroscopic appearance with histological types and subtypes was drawn, with polypoid types of "protruding superficial" and "advanced malignant" tumors reported to be "carcinosarcomas," "SCC" or "malignant melanomas." [41]. Predominantly, subepithelial types of protruding tumors were found to be small cell type undifferentiated carcinomas, basaloid SCCs or adenoid cystic carcinomas [31]. The appearance of lesions during endoscopy has been reported to be helpful in assessing the likelihood of lymph node metastasis. In particular, flat lesions are said to metastasize less likely to a lymph node than a depressed or elevated lesion [42].

The most common histopathological type in our study was squamous cell carcinoma $(52.81 \%, 47$ cases). This proportion is lower than that in studies from Ghana (78.7\%), Togo $(84.21 \%)$, Kenya where over $90 \%$ of patients diagnosed with esophageal cancer had squamous cell carcinoma [13, 18, 39]. In certain developed nations including Australia, Finland, France, United States and United Kingdom adenocarcinoma of the esophagus predominates [7]. According to Zhang, Approximately three quarters of all adenocarcinomas are found in the distal esophagus, whereas squamous-cell carcinomas are more evenly distributed between the middle and lower third [27]. Daly et al found that SCC occurs equally as often in the middle and lower esophagus, with an incidence that is three times higher in blacks in comparison to whites [43]. Enzinger et al confirmed that nearly threefourths of all ADCs are found in the distal third of esophagus, whereas SCC are more evenly distributed throughout the distal two-thirds. They found that higher incidence of distal EC in west may primarily be attributed to a higher incidence of ADC. SCC still is the predominant histological subtype in Asian nations where most of the cases occur in middle or lower third [44]. However, in their study, Mustapha et distal one-third $(30-40 \mathrm{~cm})$ was the most common site in both the sexes [21]. The diversity of the distribution of esophageal squamous cell carcinoma is demonstrated as some studies have shown that squamous cell carcinoma primarily occurs more in the middle third [22, 45]. Interestingly, patients who developed squamous cell carcinoma who neither drank alcohol nor smoked cigarette had their tumor exclusively located in the middle third of the esophagus in this study [18].

\section{Conclusion}

Malignant tumors of the esophagus are predominantly male in Cameroon and occur mainly in subjects over 50 years. Their incidence is strongly associated with alcoholtoxic intoxication. The tumor lesions sit mainly in the lower third of the organ. The most common histological type is squamous cell carcinoma.

\section{References}

[1] Ferlay J, Soerjomataram I, Dikshit R, et al. Cancer incidence and mortality worldwide: sources, methods and major patterns in GLOBOCAN 2012. Int J Cancer. 2015; 136: E359-E386.

[2] Wong MCS, Hamilton W, Whiteman DC, Jiang JY, Qiao Y, et al. Global Incidence and mortality of oesophageal cancer and their correlation with socioeconomic indicators temporal patterns and trends in 41 countries. Scientific Reports. 2018; 8: 4522. DOI: 10.1038/s41598-018-19819-8.

[3] Malhotra GK, Yanala U, Ravipati A, Follet M, et al. Global trends in esophageal cancer. J Surg Oncol. 2017; 115: 564 579 .

[4] Yousefi MS, Sharifi-Esfahani M, Pourgholam-Amiji N, Afshar M, et al. Esophageal cancer in the world: incidence, mortality and risk factors. Biomedical Research and Therapy. 2018; 5 (7): 2504-2517.

[5] Global Burden of Disease Cancer Collaboration, Fitzmaurice C, Dicker D, et al. The global burden of cancer 2013. JAMA Oncol. 2015; 1: 505-527.

[6] Pennathur A, Gibson MK., Jobe BA, Luketich, JD. Oesophageal carcinoma. Lancet. 2013; 381: 400-412. 
[7] Lepage C. Rachet B, Jooste V, Faivre J, Coleman MP Continuing rapid increase in esophageal adenocarcinoma in England and Wales. Am J Gastroenterol. 2008; 103: 2694-2699.

[8] Chen Y, Tong Y, Yang C, et al. Consumption of hot beverages and foods and the risk of esophageal cancer: a meta-analysis of observational studies. BMC Cancer. 2015; 15: 449.

[9] Lambert R, Hainaut P. Esophageal cancer: cases and causes (part I). Endoscopy. 2007; 39: 550-555.

[10] Parker RK, Dawsey SM, Abnet C, White RE. Frequent occurrence of oesophageal cancer in young people in Western Kenya. Dis Oesophagus. 2010; 23: 128-135.

[11] Engbang NJP et al. Aspects histologiques et epidémiologiques du cancer de l'oesophage à Douala. 23è Journées Scientifiques de la Société Camerounaise de Gastro-Enterologie; 23 Septembre 2016. Douala, Cameroun.

[12] Chitra S, Ashok L, Anand L, Srinivasan V, Jayanthi V. Risk factors for esophageal cancer in Coimbatore, Southern India: A hospital-based case-control study. Indian J Gastroenterol. 2004; 23: 19-21.

[13] Harouna YD, Illo A, Assoumane I, Onuoha C, Abdou I, et al. Les cancers de l'oesophage au Niger: aspects épidémiologiques et cliniques. A propos de 36 cas. Méd Afr Noire. 2008; 55 (4): 235-9.

[14] Henry MA, Lerco MM, Ribeiro PW, Rodrigues MA. Epidemiological features of esophageal cancer. Squamous cell carcinoma versus adenocarcinoma. Acta Cir Bras. 2014; 29 (6): 389-93.

[15] Brown LM, Hoover R, Silverman D, Boris D, Hayes R, et al. Excess incidence of squamosus cell esophageal cancer among US Black men: role of social class and other risk factors. Am J Epidemiol. 2001; 153 (2): 114-22. doi: 10.1093/aje/153.2.114.

[16] Patel N, Benipal B. Incidence of Esophageal Cancer in the United States from 2001-2015: A United States Cancer Statistics Analysis of 50 States. Cureus. 2018; 10 (12): e3709. DOI 10.7759/cureus.3709.

[17] Mir MM, Dar NA. Esophageal cancer in Kashmir (India): An enigma for researchers. Int J Health Sci (Qassim). 2009; 3: 71-85.

[18] Tettey M, Edwin F, Anitey E, Sereboe L, Tamatey M, et al. The changing epidemiology of esophageal cancer in subSaharan Africa-the case of Ghana. Pan African Medical Journal. 2012; 13: 6 .

[19] Pedram A, Mahmodlou R, Enshayi A, Sepehrvand N. Esophageal cancer in northwestern Iran. Indian J Cancer. 2011; 48 (2): 165-9.

[20] Nordenstedt H, El-Serag H. The influence of age, sex, and race on the incidence of esophageal cancer in the United States (19922006). Scand J Gastroenterol. 2011; 46 (5): 597-602.

[21] Mustafa SA, Banday SZ, Bhat MA, Patigaroo AR, Mir AW, Bhau KS. Clinico-Epidemiological Profile of Esophageal Cancer in Kashmir. Int J Sci Stud 2016; 3 (11): 197-202.

[22] Prikens A. Orringer M. Geographical distribution and racial disparity in esophageal cancer. Ann Thorac Surg. 2003; 76: S1367-S1369.

[23] Lin Y, Totsuka Y, He Y, Kikuchi S, Qiao Y, Ueda J, Wei W, Inoue $\mathrm{M}$, Tanaka $\mathrm{H}$. Epidemiology of esophageal cancer in Japan and China. J Epidemiol. 2013; 23 (4): 233-42. doi: 10.2188/jea.JE20120162.
[24] Wheeler GB, Reed CE. Epidemiology of esophageal cancer. Surg Clin N Am. 2012; 92: 1077-87. doi: 10.1016/j.suc.2012.07.008.

[25] Muwonge R, Ramadas K, Sankila R, Thara S, Thomas G, Vinoda J, Sankaranarayanan R. Role of tobacco smoking, chewing and alcohol drinking in the risk of oral cancer in Trivandrum, India: a nested case-control design using incident cancer cases. Oral Oncol 2008; 44: 446-454 [PMID: 17933578 DOI: 10.1016/j.oraloncology.2007.06.002].

[26] Blot W, McLaughlin J, Fraumeni JF. Esophageal Cancer. In Cancer Epidemiology and Prevention Edited. Schottenfeld D, Fraumeni J ed. New York: Oxford University Press, 2006: 697-706.

[27] Zhang Y. Epidemiology of esophageal cancer. World J Gastroenterol 2013; 19 (34): 5598-5606.

[28] Umar SB, Fleischer DE. Esophageal cancer: epidemiology, pathogenesis and prevention. Nat Clin Pract Gastroenterol Hepatol 2008; 5: 517-526 [PMID: 18679388 DOI: $10.1038 /$ ncpgasthep 1223].

[29] Brown LM, Hoover RN, Greenberg RS, Schoenberg JB, Schwartz AG, Swanson GM, Liff JM, Silverman DT, Hayes RB, Pottern LM. Are racial differences in squamous cell esophageal cancer explained by alcohol and tobacco use? J Natl Cancer Inst 1994; 86: 1340-1345 [PMID: 8064893 DOI: $10.1093 /$ jnci/86.17.1340].

[30] Lagergren J, Lagergren P. Recent developments in esophageal adenocarcinoma. CA Cancer J Clin 2013; 63 (4): 232-48. doi: $10.3322 /$ caac. 21185 .

[31] Löfdahl HE, Lu Y, Lagergren P, Lagergren J. Risk factors for esophageal adenocarcinoma after antireflux surgery. Ann Surg 2013; 257: 579-582 [PMID: 23426349 DOI: 10.1097/ SLA.0b013e3182888384].

[32] Bosetti C, Levi F, Ferlay J, Garavello W, Lucchini F, Bertuccio P, Negri E, La Vecchia C. Trends in oesophageal cancer incidence and mortality in Europe. Int J Cancer. 2008; 122: 1118-29. doi: 10.1002/ijc.23232.

[33] Islami F, Pourshams A, Kamanger F, et al. Tea drinking habits and oesophageal cancer in a high risk area in northern Iran: population based case-control study. BMJ 2009; 338: 929.

[34] Rasousli M, Ghadimi MR, Mahmoodi M, et al. Survival analysis of patients with esophageal cancer using parametric curve model. Asian Pac J Cancer Prev 2011; 12: 2359-63.

[35] Sadjadi A, Marjani H, Semnani S, Nasseri-Moghaddam S. Esophageal cancer in Iran: a review. Mid East J Cancer 2010; 1: 5-14.

[36] Kaiser HE. Cancer-promoting effects of phenols in tea. Cancer 1967; 20: 614-6.

[37] Hamrah MS, Hamrah MH, Rabi M, Wu HX, et al. Prevalence of Esophageal Cancer in the Northern Part of Afghanistan. Asian Pac J Cancer Prev. 2014; 15 (24): 10981-10984.

[38] Williams HJ, Grubb AJ, Davis WJ, Wang J-S, Jolly PE, et al. HIV and hepatocellular and esophageal carcinomas related to consumption of Mycotoxin-prone foods in sub-Saharan Africa. Am J Clin Nutr. 2010; 92 (1): 154-60. doi: 10.3945/ajen.2009.28761 
[39] Oumboma B, Mawuli L-AL, Aklesso B, Laconi K, Datouda R. Etude descriptive et analytique du cancer de l'oesophage au Togo. Pan African Medical Journal. 2014; 19: 315.

[40] Dia D, Bassene ML, Ndiaye-Bâ N, Halim A, Diallo S, Fall S, Diouf MF, Mbengue M, Diouf ML. Aspects endoscopiques du cancer de l'oesophage à Dakar (Sénégal): études de 76 observations. Méd Trop. 2011; 71 (3): 286-288.

[41] Kuwano H, Nakajima M, Miyazaki T, Kato H. Clinicopathological characteristics of esophageal squamous cell carcinoma. Ann Thorac Cardiovasc Surg. 2003; 9: 7-13.

[42] Shimada H, Nabeya Y, Matsubara H, Okazumi S, Shiratori T, Shimizu T, et al. Prediction of lymph node status in patients with superficial esophageal carcinoma: Analysis of 160 surgically resected cancers. Am J Surg 2006; 191: 250-4.

[43] Daly JM, Fry WA, Little AG, Winchester DP, McKee RF, Stewart AK, Fremgen AM. Esophageal cancer: results of an American College of Surgeons Patient Care Evaluation Study. J Am Coll Surg 2000; 190: 562-572; discussion 572-573 [PMID: 10801023 DOI: 10.1016/S1072-7515 (00) 00238-6].

[44] Enzinger PC, Mayer RJ. Esophageal cancer. N Engl J Med 2003; 349: 2241-52.

[45] Chou J, Gress F. Esophageal Cancer. http://www.health.am/cr/esophageal-cancer-diagnosis /Accessed 24th april, 2019. 